\title{
Laboratory preparedness for detection and monitoring of Shiga toxin 2-producing Escherichia coli O104:H4 in Europe and response to the 2011 outbreak
}

P Rosin (polyia.rosin@ecdc.europa.eu) ${ }^{1}$, T Niskanen², D Palm¹, M Struelens ${ }^{1}$, J Takkinen²,

Shiga toxin-producing Escherichia coli Experts of the European Union Food-and Waterborne Diseases and Zoonoses Network ${ }^{3}$

1. Microbiology Coordination section, European Centre for Disease Prevention and Control (ECDC), Stockholm, Sweden

2. Food and Waterborne Diseases and Zoonoses Programme, European Centre for Disease Prevention and Control (ECDC),

Stockholm, Sweden

3. The STEC/VTEC experts of the Network, are listed at the end of this article

Rosin P, Niskanen T, Palm D, Struelens M, Takkinen J, Shiga toxin-producing Escherichia coli Experts of the European Union Food- and Waterborne Diseases and Zoonoses Network. Laboratory preparedness for detection and monitoring of Shiga toxin 2-producing Escherichia coli O104:H4 in Europe and response to the 2011 outbreak. Euro Surveill. 2013;18(25):pii=20508. Available online: http://www.eurosurveillance.org/ViewArticle.aspx?Articleld=20508

A hybrid strain of enteroaggregative and Shiga toxin 2-producing Escherichia coli (EAEC-STEC) serotype 0104: $\mathrm{H}_{4}$ strain caused a large outbreak of haemolytic uraemic syndrome and bloody diarrhoea in 2011 in Europe. Two surveys were performed in the European Union (EU) and European Economic Area (EEA) countries to assess their laboratory capabilities to detect and characterise this previously uncommon STEC strain. Prior to the outbreak, 11 of the 32 countries in this survey had capacity at national reference laboratory (NRL) level for epidemic case confirmation according to the EU definition. During the outbreak, at primary diagnostic level, nine countries reported that clinical microbiology laboratories routinely used Shiga toxin detection assays suitable for diagnosis of infections with EAEC-STEC 0104: $\mathrm{H}_{4}$, while 14 countries had NRL capacity to confirm epidemic cases. Six months after the outbreak, 22 countries reported NRL capacity to confirm such cases following initiatives taken by NRLs and the European Centre for Disease Prevention and Control (ECDC) Food- and Waterborne Disease and Zoonoses laboratory network. These data highlight the challenge of detection and confirmation of epidemic infections caused by atypical STEC strains and the benefits of coordinated EU laboratory networks to strengthen capabilities in response to a major outbreak.

\section{Introduction}

Between May and August 2011, an outbreak of Shiga toxin 2-producing Escherichia coli (STEC) affected over 4,000 individuals in Europe. It was associated with the highest number of cases of haemolytic uraemic syndrome (HUS) reported to date (782 confirmed and 119 suspected cases) in the European Union (EU)/European Economic Area (EEA) [1]. The first cases were reported from Germany, where the laboratory characterisation of the causative bacterial strain was conducted $[2,3]$.
The outbreak strain was identified as STEC with unusual characteristics. These included the rare serotype 0104: $\mathrm{H}_{4}$, lack of attaching/effacing pathogenicity island of virulent STEC strains, as indicated by the lack of the eae gene, but harbouring virulence markers of enteroaggregative $E$. coli, e.g. presence of aggR gene, and exhibiting a multidrug resistance phenotype, including production of CTX-M-15 extended spectrum beta-lactamase (ESBL) [4-6]. At the beginning of June 2011, the European Centre for Disease Prevention and Control (ECDC) published an EU epidemic case definition for this outbreak strain [7] to allow standardised reporting by the EU/EEA countries and comparison of data at EU level for outbreak monitoring.

Epidemiological investigations conducted in Germany, France, Denmark and other countries indicated contaminated fenugreek sprouts as likely vehicle of the infections [8,9]. A trace-back global exercise, led by the European Food Safety Authority (EFSA), showed that an implicated lot of fenugreek seeds had been imported to 24 EU Member States [10].

In addition to the risk of spread of STEC 0104: $\mathrm{H}_{4}$, illustrated by STEC 0104: $\mathrm{H}_{4}$ cases in Bordeaux [11], in the early phases of this outbreak, several points raised public health concern: (i) the complexity of the detection and identification of STEC that made it difficult to diagnose cases and hampered the assessment of the effect of disease control measures, (ii) the limited sensitivity of routine diagnostic methods for detecting this serotype and pathotype that suggested potential surveillance gaps [12-15], and (iii) the unusually high rate of renal and neurological complications and death among adult cases [16-18].

The mission of ECDC is to identify, assess and communicate current and emerging threats to human health 
Availability of Shiga toxin detection tests at primary diagnostic level in European Union and European Economic Area, June 2011

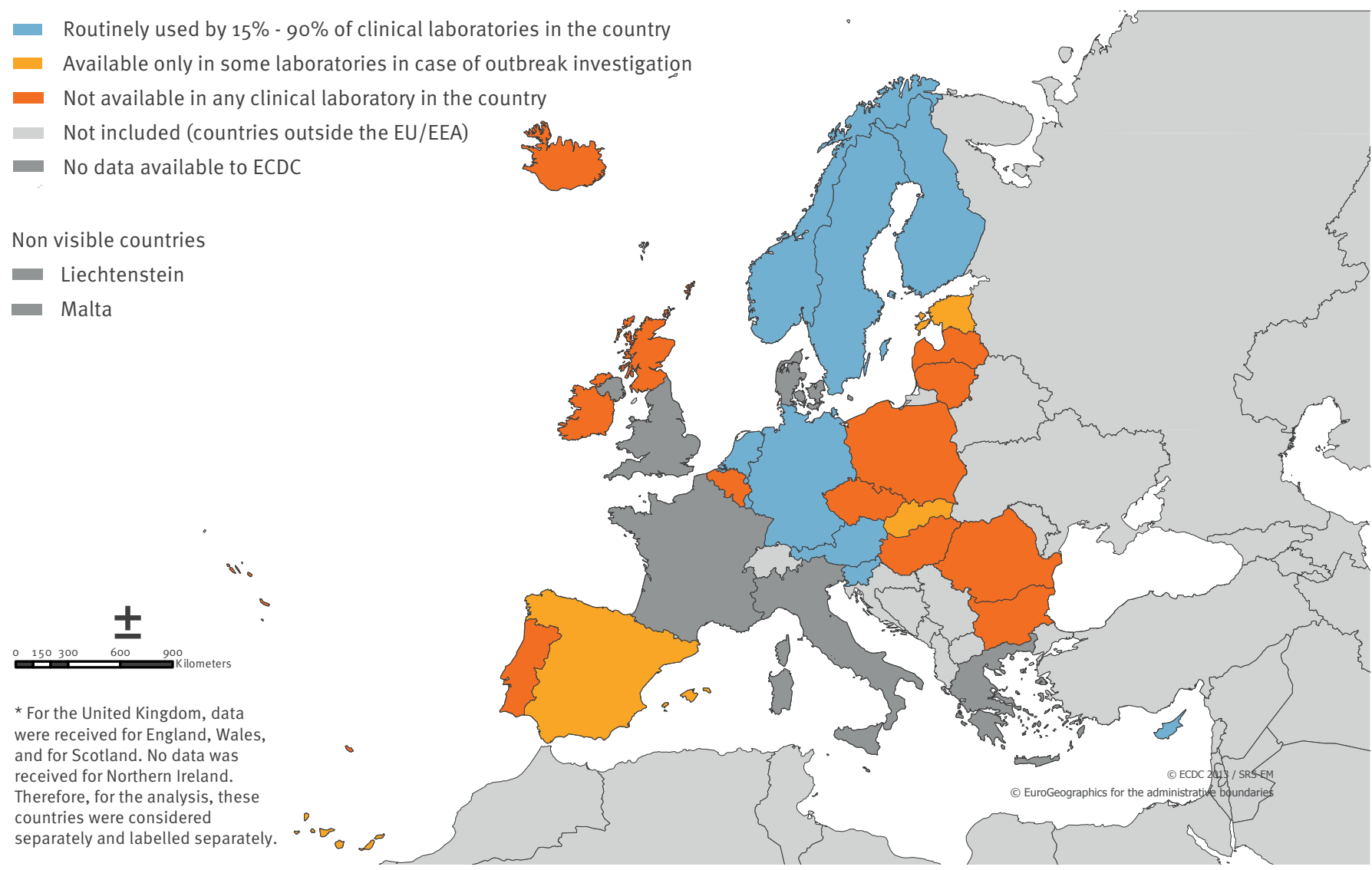

ECDC: European Centre for Disease Prevention and Control; EU/EEA: European Union/European Economic Area.

posed by infectious diseases in the EU/EEA. To adress the concerns raised in terms of laboratory diagnostics, ECDC investigated how well the EU/EEA countries were able to diagnose and confirm STEC $\mathrm{O}_{104}: \mathrm{H}_{4}$ cases according to the EU epidemic case definition and whether rapid laboratory capacity building initiatives were needed. In this article, we present the results of two laboratory capacity surveys in the EU/EEA before, during, and after the 2011 STEC 0104: $\mathrm{H}_{4}$ outbreak respectively, and describe capacity building activities taken at national and European levels in response to the outbreak.

\section{Methods}

A short questionnaire to survey laboratory practices for enabling application of the epidemic case definition and identification of the epidemic STEC 0104: $\mathrm{H}_{4}$ strain was sent by email to the STEC/VTEC contact points of the European Food- and Waterborne Diseases and Zoonoses Network (FWD-Net) on 2 June 2011 (first survey). The survey focused on availability of the following strain characterisation tests at national reference laboratory (NRL) level: $\mathrm{O}$ serogrouping, $\mathrm{H}$ serotyping, Shiga toxin 1 (stx1) and 2 gene (stx2) detection and subtyping, eae, aggR and $E A g g E C$ virulence gene detection, multilocus sequence typing (MLST) and pulsed-field gel electrophoresis (PFGE) analysis with Xbal macrorestriction. The survey also inquired about information available at national level on diagnostic capabilities in clinical microbiology practice (i.e. at primary level) for Shiga toxin and gene detection and asked to indicate the source of this informarion on primary level diagnostic capabilities. Data received by 2 July 2011 were included for the purpose of this analysis.

A follow-up survey was sent in January 2012 (second survey), assessing the NRL capabilities for STEC detection and characterisation available in April 2011 (before the outbreak) and December 2011 (after the outbreak). The survey also addressed actions taken at national level from June to December 2011 to stengthen STEC 0104: $\mathrm{H}_{4}$ diagnostic capabilities and/or reporting of cases. Furthermore, the survey participants were asked to answer whether they need services for STEC strain characterisation and to indicate the type of support expected from ECDC in STEC outbreaks and 
in general for investigation of outbreaks of emerging, highly virulent pathogenic organisms of international concern. All responses received by the end of March 2012 were included in the analysis presented here.

For the United Kingdom, data were received for England and Wales, and for Scotland. No data were received for Northern Ireland. Therefore, England and Wales, and Scotland were considered as separate countries, hence the survey comprised 32 instead of 30 EU/EEA countries. For the analysis of the data, the denominator used was 32 to allow for comparison of data between the two surveys.

To compare the proportion of countries reporting confirmed epidemic cases to the laboratory capability at clinical diagnostic level, Fisher's exact test was used with two-tailed probability.

\section{Results}

In the first survey in mid 2011, 24 of 32 countries responded to the questionnaire and in the second survey in early 2012, responses came from 29 countries, leading to response rates of $75 \%$ and $91 \%$ respectively.

\section{First survey (mid 2011)}

\section{Availability of Shiga toxin detection}

tests at primary diagnostic level

Data showed that in seven countries, information available was based on national external quality assessment results and/or national surveys of testing practices of clinical laboratories, conducted in 2010 and/or 2011.

\section{TABLE}

Routine testing for Shiga toxin genes at clinical microbiology level in European Union and European Economic Area countries reporting or not reporting confirmed epidemiological cases of Shiga toxin 2producing Escherichia coli O104:H4, July 2011

\begin{tabular}{|l|c|c|c|}
\hline \multirow{2}{*}{$\begin{array}{l}\text { Shiga toxin diagnostic } \\
\text { testing at clinical } \\
\text { laboratories }\end{array}$} & \multicolumn{2}{|c|}{$\begin{array}{c}\text { Number of countries } \\
(\mathrm{n}=32)^{\mathrm{a}}\end{array}$} & \multirow{2}{*}{ Total } \\
\cline { 2 - 4 } & Reporting & $\begin{array}{c}\text { Not } \\
\text { reporting }\end{array}$ & \\
\hline $\begin{array}{l}\text { Available in more } \\
\text { than 15\% }\end{array}$ & 6 & 3 & 9 \\
\hline $\begin{array}{l}\text { Available only in some, } \\
\text { in case of outbreaks }\end{array}$ & 1 & 2 & 3 \\
\hline Not available & 2 & 10 & 12 \\
\hline
\end{tabular}

a For the United Kingdom, data were received for England and Wales, and for Scotland. No data were received for Northern Ireland. Therefore, England and Wales, and Scotland were considered as separate countries, hence the survey comprised 32 instead of 30 European Union and European Economic Area countries.
For 17 countries, the information was based on personal communication to NRL.

Based on the information available to the NRLs, stx1 and stx 2 and/or Stx $1 / 2$ assays were routinely used in clinical laboratories in nine of the 32 countries. For these nine countries, the percentage of clinical laboratories using these assays routinely varied between 15 to $90 \%$ laboratories per country with a median of $65 \%$. According to NRLs, in three countries, such tests were used by clinical laboratories occasionally, e.g. in the case of outbreaks. Shiga toxin 1 and 2 toxin and/or gene tests were not used in clinical laboratories in 12 countries. Figure 1 shows the availability of these tests at clinical laboratory level by country in the European EU/EEA.

Of note, six of nine countries with clinical microbiology Stx/stx detection capacity had reported STEC 0104: $\mathrm{H}_{4}$ epidemic cases as compared with two of 12 countries with no capacity ( $p<0.05$, Table ).

STEC O104:H4 case confirmation capabilities at national reference laboratory level at

the time of the 2011 outbreak

The responses demonstrated that in 18 of 32 countries, $\mathrm{O}_{104}$ serogrouping test was available, while $\mathrm{H}_{4}$ serotyping test was available in 14 countries. Tests for detection of stx1/stx2, eae and aggR were available in 20,19 , and 14 countries, respectively.

Analyses with PFGE using $X b a l$ macrorestriction according to the PulseNet protocol were available in 18 NRLs and MLST was performed only in five laboratories .

The data on the availability of the above tests showed that 14 NRLs were capable of confirming an outbreakrelated case according to the EU epidemic case definition. In four additional countries, the NRLs were able to confirm cases only if epidemiological criteria were met. In six countries the NRLs reported lack of specific tests for confirmation of epidemic STEC 0104: $\mathrm{H}_{4}$ cases.

\section{Second survey (early 2012)}

Capabilities of NRLs for case detection and identification of STEC O104:H4

before and after the 2011 outbreak

Data obtained revealed that prior to the STEC 0104: $\mathrm{H}_{4}$ outbreak in April 2011, 11 of 32 countries had NRL capacity to confirm STEC 0104: 44 cases. In December 2011, five months after the outbreak, 22 countries reported such NRL capacity ( $p<0.05$, Figure 2 ).

There was an increase in the number of STEC detection and identification methods at NRL level in December 2011 compared with April 2011 (Figure 3). The change was most pronounced for methods required for STEC 0104: 44 case confirmation. From April to December 2011, 15 countries had developed 0104 serogrouping capability, eight $\mathrm{H}_{4}$ serotyping capability, six aggR detection test and four stx1/2 and eae detection tests. 


\section{FIGURE 2}

Capabilities of national reference laboratories in the European Union and European Economic Area for case detection and identification of Shiga toxin 2-producing Escherichia coli O104:H4 before and after the 2011 outbreak, March 2012

\section{A: April 2011}

stx $1 / 2$ gene subtyping, $\mathrm{O}$ serogrouping, $\mathrm{H}$ serotyping

- No capacity for STEC 0104: $\mathrm{H}_{4}$ case confirmation

- No data available to ECDC

Not included (countries outside the EU/EEA)

Non visible countries

Liechtenstein

- Malta
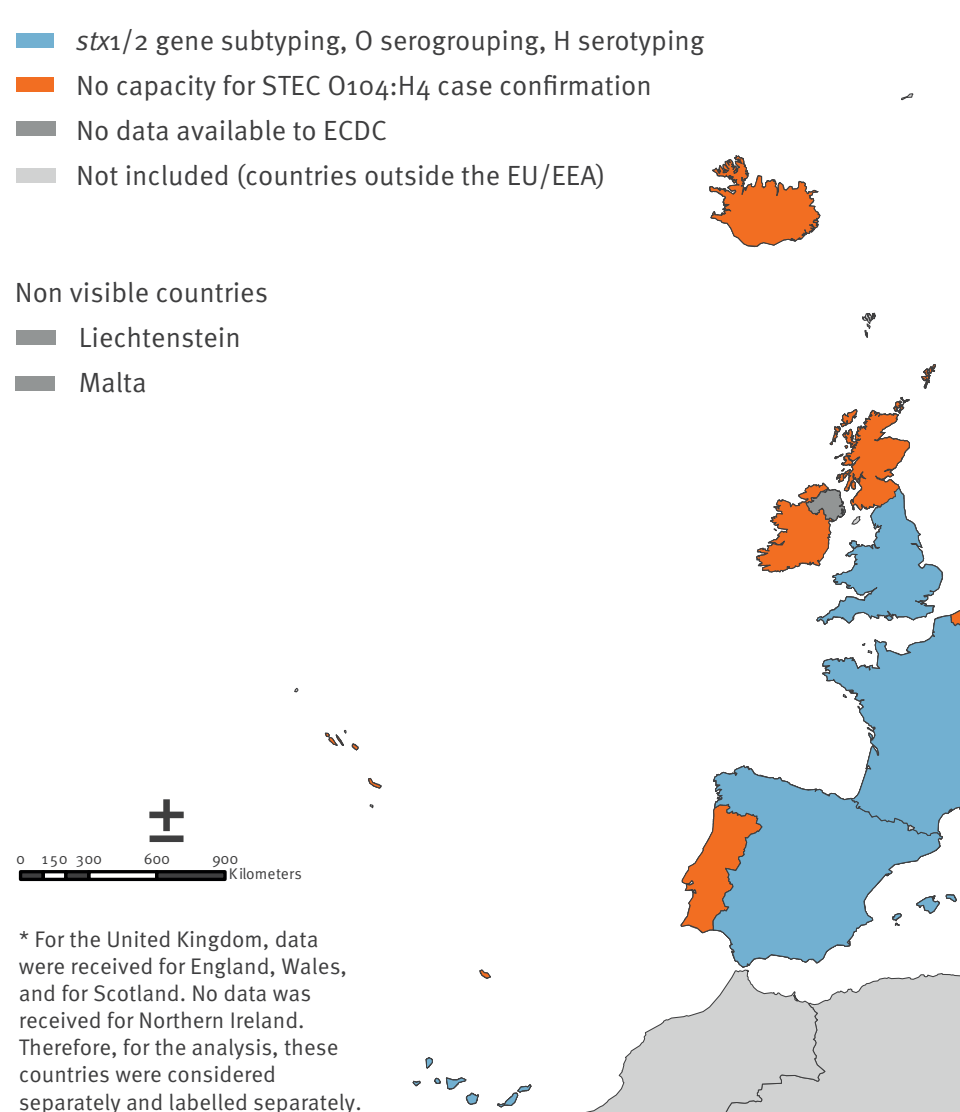

separately and labelled separately.

\section{B: December 2011}

stx1/2 gene subtyping, $O$ serogrouping, $\mathrm{H}$ serotyping

- $s t \times 1 / 2$ gene subtyping, 0 serogrouping and epidemiological criteria

No capacity for STEC $0_{104}: \mathrm{H}_{4}$ case confirmation

not included (countries outside the EU/EEA)

No data available to ECDC

Non visible countries

Liechtenstein

Malta

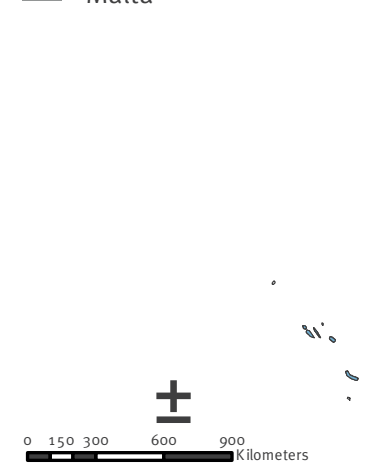

* For the United Kingdom, data were received for England, Wales, and for Scotland. No data was received for Northern Ireland. Therefore, for the analysis, these countries were considered
separately and labelled separately. $\therefore$
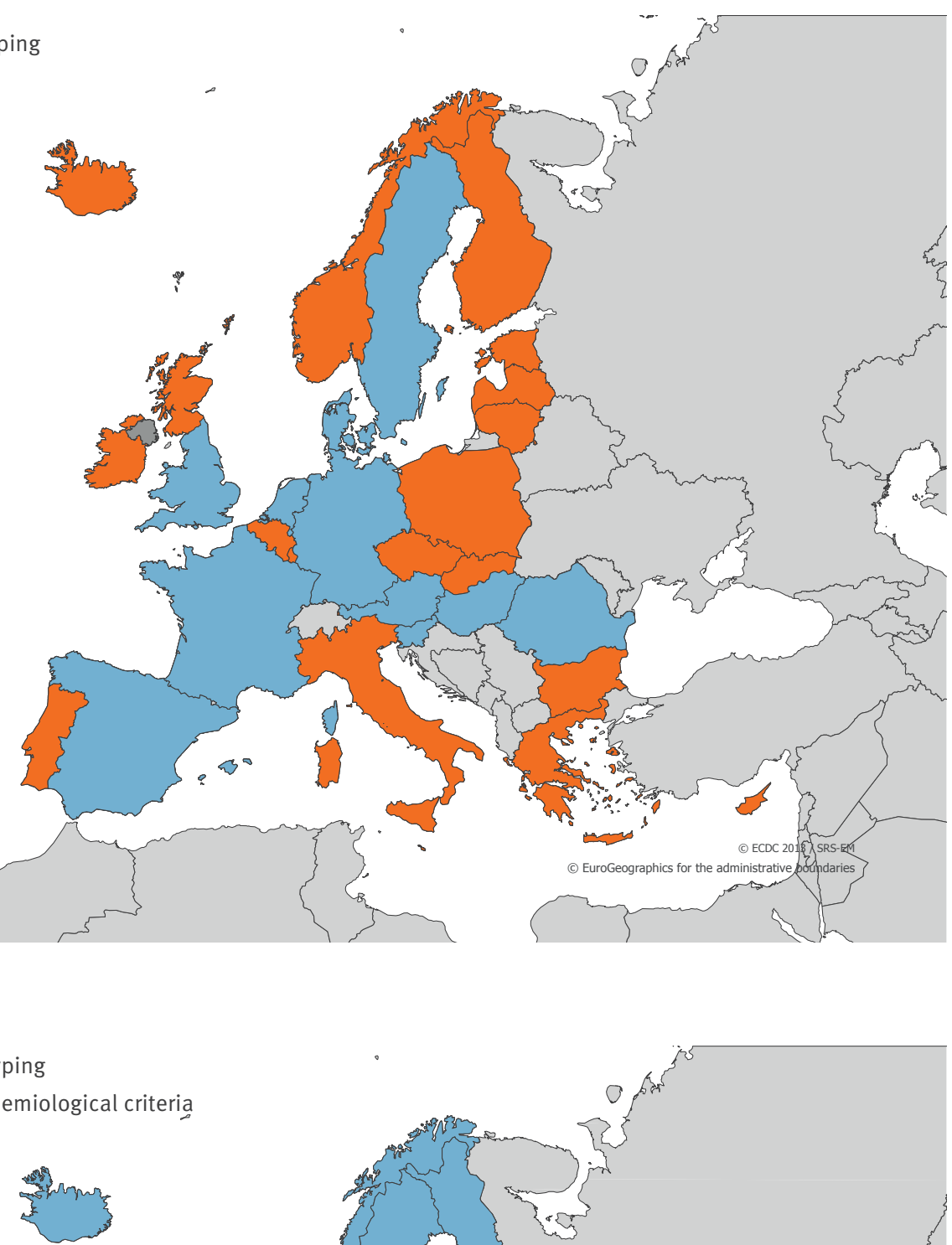

ECDC: European Centre for Disease Prevention and Control; EU/EEA: European Union/European Economic Area; STEC: Shiga toxin 2-producing Escherichia coli. 
Number of Shiga toxin 2-producing Escherichia coli detection and identification methods at national reference laboratories in the European Union and European Economic Area before and after the 2011 outbreak in Europe

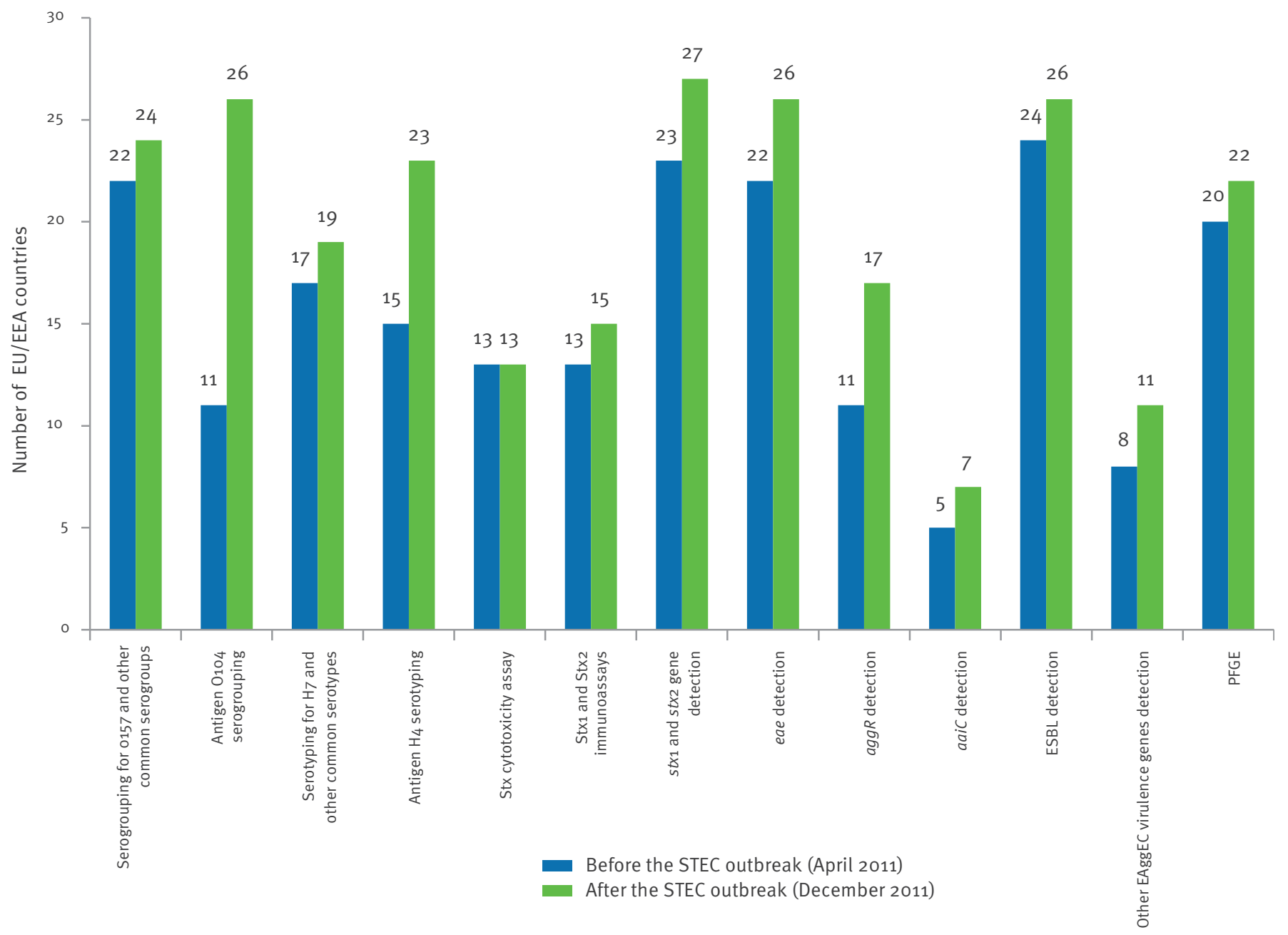

ESBL: extended spectrum beta-lactamase; EU/EEA: European Union/European Economic Area; PFGE: pulsed-field gel electrophoresis; STEC: Shiga toxin 2-producing Escherichia coli.

In April 2011, 24 countries reported capabilities for assessing ESBL production: 12 countries reported testing for both gene detection and phenotypic characterisation, and another 12 used phenotypic characterisation alone. In December 2011, 26 countries tested for ESBL at NRL level: 14 used phenotypic detection alone, 11 countries used both phenotypic characterisation and genotypic detection and one tested for ESBL production based on gene detection alone.

Twenty-six countries indicated that specific actions had been taken at national level during and/or following the outbreak to increase STEC 0104: $\mathrm{H}_{4}$ detection capabilities. Such actions were directed at primary microbiology diagnostic services in the form of (i) guidance on diagnostic methods for 23 countries, (ii) pathogen isolation and referral of isolates in 21, and (iii) case reporting in 20 countries. Recommendations regarding $E$. coli strain characterisation methods as well as participation in ad hoc external quality assessment (EQA) schemes for diagnostic services were given to clinical laboratories in 10 EU/EEA countries.

\section{Needs for inter-laboratory services for Shiga} toxin-producing $E$. coli strain characterisation Despite these efforts to increase capability for STEC detection and characterisation, nine countries reported needs for access to strain characterisation services from a reference laboratory in another country, including for serotyping of rare STEC serogroups and MLST. Two countries reported NRL service arrangements with reference laboratories in other countries for testing rare STEC serotypes. 
Initiatives expected from ECDC to support national response to outbreaks of emerging, highly virulent pathogenic organisms of international concern The needs most frequently mentioned included (i) early warning and information exchange (17 countries), (ii) protocols for pathogen isolation and detection (13 countries), and (iii) provision of diagnostic materials and reagents (12 countries). One country did not expect any support.

\section{Discussion}

Human infections caused by STEC 0157:H7 account for nearly half of reported cases of STEC disease in the EU/EEA countries [19]. Non-0157 serotypes are much less commonly reported as causes of human disease, mainly due to weight of diagnostics towards identification of 0157 serogroup. The large STEC outbreak in 2011 in the EU/EEA was caused by the rare serotype and atypical enteroaggregative pathotype STEC 0104: $\mathrm{H}_{4}$. Considering the impact of this outbreak and its spread across borders, it was essential to assess the capacity of EU/EEA countries to confirm epidemic cases and to target any necessary capacity building activities. The results from such assessement presented here show that during this STEC 0104:H4 outbreak, several countries lacked the capacity at national level to detect and characterise STEC 0104: $\mathrm{H}_{4}$ cases according to the EU epidemic case definition [7]. Importantly, even greater case detection gaps existed at primary diagnostic level, based on the information reported by NRLs. Diagnostic capability at clinical laboratory level by use of Shiga toxin detection for non-0157 STEC was associated with more frequent reporting of epidemic cases of this rare STEC serotype. Diagnostic and characterisation capacity at NRL level may compensate in part for lack of routine Shiga toxin testing at primary level. However, at the onset of the outbreak, two-thirds of the EU/EEA countries reported no NRL capacity for confirmation of STEC $0_{104}: \mathrm{H}_{4}$ cases, which along with the lack of routine Shiga toxin screening in clinical laboratories, raises the possibility that previous outbreaks of STEC strains of rare serotypes/pathotypes, might have not been detected. This indicates an inadequate level of preparedness of Europe's public health microbiology system to detect early unusual events, such as the emergence of new pathotypes of STEC. It underlines the need to strengthen the microbiology laboratory capacity for timely communicable disease alert and response.

Our study has some limitations: information on clinical laboratories testing practices was based to a large extend on personal communication to NRLs (i); availability of Shiga toxin gene detection tests at NRL level and not that of Stx1 and Stx2 immunoassays was assessed in the first survey (ii); the results of the first survey should be interpreted with caution since it was conducted during the outbreak when testing practice was subject to changes and because it received a lower response rate than the second survey (iii). Nevertheless, our findings of low capacity for detection of non-0157 STEC infections are in line with observations made by others. A survey of laboratory practices for identification of STEC as part of the United States (US) Foodborne Diseases Active Surveillance Network showed that only $11 \%$ of laboratories used a method that would detect non-0157 STEC [20]. It is noteworthy that in this survey, conducted in 2007 only half of the laboratories routinely tested all specimens for non0157 STEC. Another study conducted within the same network, showed that besides the available laboratory capacities, the correct identification of STEC infections also depended on physicians knowledge of STEC and ability to correctly interpret a positive Shiga toxin test result [21]. Thus, laboratory diagnostic and reference testing capacity would not be sufficient for timely and reliable surveillance unless clinical samples and isolates are collected for testing.

Amplification of DNA can be useful for rapid STEC detection in stool specimens [22,23] and has been shown to be cost-effective for diagnosing infections with STEC 0157 and other intestinal pathogens [24]. However, when used without culture confirmation, such tests could generate high rates of false positive results, leading to over-reporting and unnecessary treatment and public health measures [25]. In addition to that, referral of STEC isolates to NRLs is needed to perform epidemiological typing in support to cluster detection and source tracing. Due to the ongoing consolidation of clinical laboratory services and increased use of culture-independent diagnostic techniques, the importance of culture confirmation could be overlooked and thus impede microbiological outbreak investigations. Although we could not find any published data illustrating how epidemiological investigations were hampered due to lack of timely culture confirmation in Europe, such information is available from the US $[20,25]$. In this context, the post-outbreak increase in NRL capabilities to characterise STEC 0104: $\mathrm{H}_{4}$ isolates does not guarantee preparedness of EU/EEA public health microbiology system to detect this rare serotype and pathotype. It critically depends on primary case ascertainment by clinical diagnostic testing practice for non-0157 STEC and referral of isolates for reference testing.

In Europe, external quality assessment of NRL capabilities to characterise non-0157 STEC in the FWD-Net laboratories, showed that typing proficiency varied depending on serotype with better performance for STEC 0157: $\mathrm{H}_{7}$ than other, less commonly reported serotypes [26]. Another survey of services of NRLs in EU/EEA countries for detection and characterisation of STEC, Campylobacter, Listeria monocytogenes, Salmonella, Shigella and Yersinia showed gaps in the capacity and reproducibility of methods used for their early detection and characterisation [27]. Capacity strengthening actions and method harmonisation are undertaken at EU/EEA level, via the ECDC Food- and Waterborne Diseases and Zoonoses programme and 
FWD-Net, to ensure that Europe has a reliable surveillance system for enteric pathogens.

This study shows increased EU/EEA NRL capabilities for STEC detection and characterisations following the 2011 STEC 0104:H4 outbreak. This is due to efforts taken at national and EU/EEA levels. At national level, measures were implemented to increase referral of specimens from suspected cases of STEC $\mathrm{O}_{104}: \mathrm{H}_{4}$ to the NRL and increase the NRL's capabilities to detect epidemic cases. At EU level, rapid development of novel PCR-based diagnostic methods and sharing of these protocols through the laboratories in the FWDNet contributed to strengthening the capacity to detect and confirm STEC 0104:H4 cases in NRLs $[6,28,29]$. In early June, ECDC published the EU epidemic case definition and issued technical guidance on microbiological testing methods on its website and provided links to expert sources of information in the EU/EEA countries [30]. In addition, ECDC supplied the NRLs in the EU/EEA countries with specific diagnostic reagents and reference materials as requested. Eighteen NRLs received $\mathrm{O}_{104}$ anti-serum and 19 received $\mathrm{K} 9$ anti-serum and enteroaggregative STEC control strains, with different $\mathrm{O}: \mathrm{H}$ combinations and stx subtypes, including a STEC 0104: $\mathrm{H}_{4}$ strain.

These rapid and coordinated capacity building efforts for STEC detection and characterisation illustrate the importance of the EU network and participating NRLs to work in close collaboration with the EU food safety experts and respective national laboratories. The rapid exchange of information at EU level during this outbreak was key in the coordination of such efforts. The existing Epidemic Intelligence Information System for FWD (EPIS FWD) facilitated the cooperation between FWD-Net laboratories. The EU Reference Laboratory for STEC/VTEC, operating in the area of food and feed safety, rapidly developed a validated laboratory protocol to detect this particular pathotype in food and environmental samples and shared this protocol through EPIS FWD [29]. ECDC also produced rapid risk assessments and EU epidemiological updates during the outbreak. A toolkit for investigation of and response to food- and waterborne disease outbreaks with an EU dimension was published in February 2012 and is available on the ECDC website. For enhanced surveillance of STEC/VTEC, the European Surveillance System (TESSy) metadataset was revised by including new variables on specific genes, i.e. aggR and $a a i C$, for reporting of STEC.

In conclusion, Europe's public health microbiology laboratory capacity such as that reported for monitoring emerging STEC outbreaks has been improved via dedicated resources at national level and via cross-sector and cross-border collaborations conducted by public health institutions to support timely and reliable surveillance for disease control.
The STEC/VTEC experts of the European Food- and Waterborne Diseases and Zoonoses Network

The members of the network, who provided the survey data are:

Austria - Sabine Schlager at the National Reference Center (NRC) for Escherichia coli including Verotoxin producing E. coli;

Belgium - Denis Pierard at the NRC VTEC/STEC, Universitair Ziekenhuis Brussel;

Bulgaria - Petar Petrov of the NRL for Enteric Pathogens, Sofia

Cyprus - Panayiota Maikanti-Charalampous at the Reference laboratory for Salmonella and other enteric pathogens;

Czech Republic - Monika Marejkova at the NRL for E. coli and Shigella;

Germany - Angelika Fruth and Rita Prager at the NRC for Salmonella and other enteric bacteria at the Robert Koch Institute;

Denmark - Flemming Scheutz of the WHO Collaborating Centre for Reference and Research on Escherichia and Klebsiella;

Estonia - Rita Peetso at the Central Laboratory of Communicable diseases, Health Board,

Finland - Anja Siitonen and Ulla-Maija Nakari at the Bacteriology Unit, National Institute for Health and Welfare; France - Malika Gouali at the Centre National de Référence des Salmonella, E. coli et Shigella, Institut Pasteur

Greece - Kassiani Mellou from the Greek Centre for Disease Control in collaboration with Reference Laboratories as the Head of Foodborne Diseases Section,

Hungary - Mária Herpay at the National reference laboratory for enteric pathogens;

Iceland - Hjordis Hardardottir at the Department Of Clinical Microbiology, Landspitali University Hospital;

Ireland - Anne Carroll and Eleanor McNamara of the Public Health Laboratory;

Italy - Alfredo Caprioli at Istituto Superiore di Sanità,

Latvia - Solvita Selderina at the East Clinical University Hospital „Infectology Center of Latvia”

Lithuania - Ruta Jankauskiene of the Lithuanian National Public Health Surveillance Laboratory;

Luxembourg - Catherine Ragimbeau at the National Health Laboratory;

Netherlands - Max E.O.C. Heck of the Laboratory for Infectious Diseases and Perinatal Screening;

Norway - Astrid Louise Wester from the NRL on Enteropathogenic bacteria;

Poland - Jolanta Szych at the Laboratory of Enteric Rods;

Portugal - Jorge Machado from the Laboratório Nacional de Referência de Infeções Gastrointestinais - Lab. de Salmonella, E. coli e outras bactérias entéricas;

Romania - Codruta-Romanita Usein at the Molecular Epidemiology Laboratory and Bacterial Enteric Infections Laboratory;

Sweden - Cecilia Jernberg of the Swedish Institute for Communicable Disease Control;

Slovenia - Marija Trkov, Laboratory of Medical Microbiology, National Institute of Public Health and Eva Grilc Department of Communicable Diseases, National Institute of Public Health;

Slovak Republic - Zuzana Sirotna at the NRC of Environmental Microbiology, Public Health Authority

Spain - Silvia Herrera León at the Reference Laboratory for E. coli, National Centre for Microbiology, Institute of Health Carlos III;

England and Wales - Claire Jenkins at the Gastrointestinal Infections Reference Unit;

Scotland - Mary Hanson at the Scottish E. coli 0157/ VTEC Reference Laboratory. 
We thank all members of the European Food-and Waterborne Diseases and Zoonoses Network for contributing data and Denis Coulombier for his support initiating this work.
3. Frank C, Werber D, Cramer JP, Askar M, Faber M, an der Heiden $M$, et al. Epidemic profile of Shiga-toxin-producing Escherichia coli 0104: $\mathrm{H}_{4}$ outbreak in Germany. N Engl J Med. 2011;365(19):1771-80. http://dx.doi.org/10.1056/ NEJMoa1106483. PMid:21696328.

4. Robert Koch Institute (RKI). Final presentation and evaluation of epidemiological findings in the EHEC 0104: 44 Outbreak, Germany 2011. Berlin: RKI. Sept 2011. Available from: http://www.rki.de/EN/Home/EHEC final report.pdf;jsessionid $=504 \mathrm{CAC}_{52} \mathrm{EE}_{1} \mathrm{C}_{9} \mathrm{~F}_{1} \mathrm{~B}_{9} \mathrm{CAD}_{341} \mathrm{~A}_{5}$ 2E23699.2_cid390?__blob=publicationFile

5. Bielaszewska M, Mellmann A, Zhang W, Kock R, Fruth A Bauwens A, et al. Characterisation of the Escherichia coli strain associated with an outbreak of haemolytic uraemic syndrome in Germany, 2011: a microbiological study. Lancet Infect Dis. 2011;11(9):671-6. PMid:21703928.

6. Scheutz F, Møller Nielsen E, Frimodt-Møller J, Boisen $\mathrm{N}$, Morabito S, Tozzoli R, et al. Characteristics of the enteroaggregative Shiga toxin/verotoxin-producing Escherichia coli $\mathrm{O}_{10}: \mathrm{H}_{4}$ strain causing the outbreak of haemolytic uraemic syndrome in Germany, May to June 2011. Euro Surveill. 2011;16(24):pii=19889. Available from: http:// www.eurosurveillance.org/ViewArticle.aspx?Articleld=19889. PMid:21699770.

7. European Centre for Disease Prevention and Control (ECDC). EU case definition for diarrhoea and haemolytic uremic syndrome (HUS) caused by the epidemic strain Shiga toxin 2-producing Escherichia Coli (STEC) 0104:H4. Stockholm: ECDC. 2011. Available from: http://ecdc.europa.eu/en/healthtopics/ escherichia_coli/epidemiological_data/Pages/EU_case definition.aspx

8. Buchholz U, Bernard H, Werber D, Bohmer MM, Remschmidt C, Wilking H, et al. German outbreak of Escherichia coli $0_{104}: \mathrm{H}_{4}$ associated with sprouts. N Engl J Med. 2011;365(19):1763-70. http://dx.doi.org/10.1056/NEJMoa1106482. PMid:22029753.

9. King LA, Nogareda F, Weill FX, Mariani-Kurkdjian P, Loukiadis E, Gault G, et al. Outbreak of Shiga toxin-producing Escherichia coli $\mathrm{O}_{104}: \mathrm{H}_{4}$ associated with organic fenugreek sprouts, France, June 2011. Clin Infect Dis. 2012;54(11):1588-94. http:// dx.doi.org/10.1093/cid/cis255. PMid:22460976.

10. European Food Safety Authority (EFSA). Technical Report. Tracing seeds, in particular fenugreek (Trigonella foenumgraecum) seeds, in relation to the Shiga toxin-producting $\mathrm{E}$. coli (STEC) 0104:H4 2011 Outbreaks in Germany and France. Parma: EFSA; 2011. Available from: http://www.efsa.europa. eu/en/supporting/pub/176e.htm

11. Gault G, Weill FX, Mariani-Kurkdjian P, Jourdan-da Silva N, King $\mathrm{L}$, Aldabe B, et al. Outbreak of haemolytic uraemic syndrome and bloody diarrhoea due to Escherichia coli $\mathrm{O}_{104}: \mathrm{H}_{4}$, southwest France, June 2011. Euro Surveill. 2011;16(26): pii=19905. Available from: http://www.eurosurveillance.org/ViewArticle. aspx?Articleld $=19905$

12. Blanco JE, Blanco M, Alonso MP, Mora A, Dahbi G, Coira MA, et al. Serotypes, virulence genes, and intimin types of Shiga toxin (verotoxin)-producing Escherichia coli isolates from human patients: prevalence in Lugo, Spain, from 1992 through 1999. j Clin Microbiol. 2004;42(1):311-9. http://dx.doi.org/10.1128/ JCM.42.1.311-319.2004. PMid:14715771. PMCid:321739.

13. Buvens G, De Gheldre Y, Dediste A, de Moreau Al, Mascart $\mathrm{G}$, Simon $A$, et al. Incidence and virulence determinants of verocytotoxin-producing Escherichia coli infections in the Brussels-Capital Region, Belgium, in 2008-2010. J Clin Microbiol. 2012;50(4):1336-45. http://dx.doi.org/10.1128/ JCM.05317-11. PMid:22238434. PMCid:3318570.

14. Caprioli A, Tozzi AE, Rizzoni G, Karch H. Non-0157 Shiga toxin-producing Escherichia coli infections in Europe. Emerg Infect Dis. 1997;3(4):578-9. http://dx.doi.org/10.3201/ eido304.970425. PMid:9366613. PMCid:2640089.

15. van Duynhoven YT, Friesema IH, Schuurman T, Roovers A, van Zwet AA, Sabbe LJ, et al. Prevalence, characterisation and clinical profiles of Shiga toxin-producing Escherichia coli in The Netherlands. Clin Microbiol Infect. 2008;14(5):43745. http://dx.doi.org/10.1111/j.1469-0691.2008.01963.x. PMid:18325039.

16. Askar M, Faber MS, Frank C, Bernard H, Gilsdorf A, Fruth A, et al. Update on the ongoing outbreak of haemolytic uraemic syndrome due to Shiga toxin-producing Escherichia coli (STEC) serotype 0104, Germany, May 2011. Euro Surveill. 2011;16(22): pii=19883. Available from: http://www. eurosurveillance.org/ViewArticle.aspx?Articleld=19883

17. Cordesmeyer S, Peitz U, Gödde N, Kasper HU, Hoffmann MW, Allemeyer E. Colonic ischaemia as a severe Shiga toxin/ verotoxin producing Escherichia coli $\mathrm{O}_{104}: \mathrm{H}_{4}$ complication in a patient without haemolytic uraemic syndrome, Germany, June 2011. Euro Surveill. 2011;16(25):pii=19895. Available from: http://www.eurosurveillance.org/ViewArticle. aspx?Articleld=19895. PMid:21722614. 
18. Magnus T, Rother J, Simova O, Meier-Cillien M, Repenthin J, Moller $\mathrm{F}$, et al. The neurological syndrome in adults during the 2011 northern German E. coli serotype 0104:H4 outbreak. Brain. 2012;135(Pt 6):1850-9. http://dx.doi.org/10.1093/brain/ aws090. PMid:22539260.

19. European Centre for Disease Prevention and Control (ECDC) and European Food Safety Authority (EFSA). Shiga toxin/verotoxinproducing Escherichia coli in humans, food and animals in the EU/EEA, with special reference to the German outbreak strain STEC 0104. Stockholm: ECDC; 2011. Available from: http:// ecdc.europa.eu/en/publications/Publications/1106_TER_EColi_ joint_EFSA.pdf

20. Hoefer D, Hurd S, Medus C, Cronquist A, Hanna S, Hatch J, et al. Laboratory practices for the identification of Shiga toxinproducing Escherichia coli in the United States, FoodNet sites, 2007. Foodborne Pathog Dis. 2011;8(4):555-60. http://dx.doi. org/10.1089/fpd.2010.0764. PMid:21186994.

21. Clogher P, Hurd S, Hoefer D, Hadler JL, Pasutti L, Cosgrove $\mathrm{S}$, et al. Assessment of physician knowledge and practices concerning Shiga toxin-producing Escherichia coli infection and enteric illness, 2009, Foodborne Diseases Active Surveillance Network (FoodNet). Clin Infect Dis. 2012;54 Suppl 5:S446-52. http://dx.doi.org/10.1093/cid/cis246. PMid:22572668.

22. El Sayed Zaki M, El-Adrosy H. Diagnosis of Shiga toxin producing Escherichia coli infection, contribution of genetic amplification technique. Microbes Infect. 2007;9(2):2003. http://dx.doi.org/10.1016/j.micinf.2006.11.005. PMid:17223372.

23. Gerritzen A, Wittke JW, Wolff D. Rapid and sensitive detection of Shiga toxin-producing Escherichia coli directly from stool samples by real-time PCR in comparison to culture, enzyme immunoassay and Vero cell cytotoxicity assay. Clin Lab. 2011;57(11-12):993-8. PMid:22239032.

24. Abubakar I, Irvine L, Aldus CF, Wyatt GM, Fordham R, Schelenz $S$, et al. A systematic review of the clinical, public health and cost-effectiveness of rapid diagnostic tests for the detection and identification of bacterial intestinal pathogens in faeces and food. Health Technol Assess. 2007;11(36):1-216. PMid:17803865.

25. Importance of culture confirmation of shiga toxin-producing Escherichia coli infection as illustrated by outbreaks of gastroenteritis--New York and North Carolina, 2005. MMWR Morb Mortal Wkly Rep. 2006;55(38):1042-5. PMid:17008867.

26. European Centre for Disease Prevention and Control (ECDC). External quality assurance scheme for typing of verocytotoxin-producing E. coli (VTEC). Stockholm: ECDC; 2012. Available from: http://ecdc.europa.eu/en/publications/ Publications/1204-TER-EQA-VTEC.pdf

27. European Centre for Disease Prevention and Control (ECDC). Survey of National Reference Laboratory capacity for six FWD in EU/EEA countries. Stockholm: ECDC; 2012. Available from: http://ecdc.europa.eu/en/publications/Publications/SurveyNRL-capacity-for-food-waterborne-agents.pdf

28. Struelens MJ, Palm D, Takkinen J. Enteroaggregative, Shiga toxin-producing Escherichia coli $0104: \mathrm{H}_{4}$ outbreak: new microbiological findings boost coordinated investigations by European public health laboratories . Euro Surveill. 2011;16(24):pii=19890. Available from: http://www. eurosurveillance.org/ViewArticle.aspx?Articleld=19890. PMid:21699771.

29. Istituto Superiore di Sanità (ISS). EU Reference Laboratory for E. coli. Department of Veterinary Public Health and Food Safety Unit of Foodborne Zoonoses. Detection and identification of Verocytotoxin-producing Escherichia coli (VTEC) $\mathrm{O}_{104}: \mathrm{H}_{4}$ in food by Real Time PCR. 13 Jun 2011. Rome: ISS. Available from: http://www.iss.it/binary/vtec/cont/Lab_proc_0104_rev2.pdf

30. European Centre for Disease Prevention and Control (ECDC). Escherichia coli. Stockholm: ECDC. [Accessed 20 Jun 2013]. Available from: http://ecdc.europa.eu/en/healthtopics/ escherichia_coli/Pages/index.aspx 